\title{
Studi Operasi Paralel Jaringan Distribusi yang Disuplai oleh Satu Gardu Induk pada Sistem Kelistrikan Distribusi Jawa Tengah. Studi Kasus : GI Srondol Semarang
}

\author{
Muhammad Khoirul Anam, Ontoseno Penangsang, dan Soedibyo. \\ Departemen Teknik Elektro, Fakultas Teknologi Elektro, Institut Teknologi Sepuluh Nopember (ITS) \\ e-mail: ontosenop@ee.its.ac.id
}

\begin{abstract}
Abstrak-Jaringan distribusi tenaga listrik biasanya beroperasi menggunakan sistem distribusi radial, untuk meningkatkan keandalan jaringan distribusi dari sisi kualitas serta kontiyuitas penyaluran daya listriknya perlu dilakukan modifikasi sistem distribusi dari radial menjadi loop, perubahan jaringan distribusi terjadi ketika dibutuhkan pelimpahan daya dari satu penyulang ke yang lainnya, sebagai tindakan pencegahan dari kelebihan beban atau bahkan pemutusan beban. Sebagai contoh dalam kasus kegagalan operasi paralel di penyulang gardu induk Srondol pada kelistrikan distribusi Jawa Tengah. Dari hasil penelitian ini, didapatkan bahwa analisis yang akurat dan tepat dari kondisi eksisting penyulang yang akan diparalel dapat membantu untuk keberhasilan operasi sistem distribusi, menghindari gangguan yang signifikan dan mencegah terjadinya pemadaman pelanggan. Pada kondisi normal dari hasil simulasi Load Flow ETAP diperoleh trafo 2 GI Srondol mengalami overload sebesar 799 A, sehingga menghindari pemadaman diperlukan pelimpahan beban. Dari operasi paralel penyulang SRL 1 dan SRL 3 terjadi peningkatan arus yang signifikan pada penyulang SRL 1 sebesar 588 A yang mengakibatkan CB SRL 1 menjadi trip, sehingga terjadi pelimpahan beban ke trafo 2 sebesar 1094 A dan mengakibatkan pemadaman total pada trafo 2. Sedangkan saat operasi paralel penyulang SRL 2 dan SRL 3 peningkatan arus yang terjadi lebih kecil, sehingga sistem masih dalam kondisi aman dan proses pelimpahan beban berhasil dilakukan.
\end{abstract}

Kata Kunci-Jaringan Distribusi, Operasi Paralel, Peningkatan Arus.

\section{PENDAHULUAN}

$\mathrm{D}$ ALAM pengoperasian sistem tenaga listrik hal yang harus dipastikan adalah kualitas dan kontinyuitas penyaluran daya listrik agar tetap dalam kondisi yang stabil. Kualitas listrik dapat diukur berdasarkan nilai dari tegangan dan frekuensinya. Sedangkan kontiyuitas penyaluran daya listrik diukur dengan transfer daya yang terus menerus atau dengan meminimalisir pemadaman [1].

Selama ini paralelisasi penyulang sistem distribusi radial untuk mentransfer daya dari beban penyulang satu ke penyulang yang lain banyak digunakan dalam sistem kelistrikan distribusi maupun transmisi. Mendistribusikan beberapa penyulang beban atau lebih bersifat paralel dari gardu induk yang sama atau berbeda dapat meningkatkan keandalan dan efisiensi. Ketika penyulang dioperasikan paralel arus yang melalui penyulang, dan total arus yang melalui beberapa bagian penyulang yang terkoneksi bisa melebihi batas kemampuan hantaran arusnya atau melebihi setting pengaman yang sudah ditentukan. Keterbatasan yang lain dari sistem paralel adalah kemampuan interupsi peralatan sectionalizing yang digunakan untuk memutus atau mengamankan jalur percabangan untuk menyelesaikan pemindahan beban [2]. Sebagai contoh dalam kasus kegagalan operasi yang pernah terjadi pada penyulang gardu induk Srondol Semarang tanggal 25 September 2017 lalu yang mengakibatkan circuit breaker pada outgoing penyulang SRL 01 dan incoming trafo 2 menjadi terbuka atau trip (PT. PLN APD Jateng \& DIY).

Dalam tugas akhir ini dibahas mengenai metodologi untuk menganalisis kelayakan teknis dari paralelisasi dalam jaringan distribusi yang dilayani oleh penyulang dan trafo yang berbeda, serta menentukan faktor-faktor keberhasilan maupun penyebab dari kegagalan operasi paralel dengan menggunakan Software Electrical Transient Analysis Program (ETAP). Sehingga bisa meningkatkan kualitas dan kontiyuitas layanan serta dapat meminimalisir pemadaman listrik bagi pelanggan.

\section{SISTEM JARINGAN DISTRIBUSI $20 \mathrm{KV}$}

\section{A. Sistem Distribusi Tenaga Listrik}

Sistem distribusi tenaga listrik merupakan bagian dari sistem tenaga listrik yang berfungsi sebagai penyaluran dan pembagian listrik kepada pelanggan melalui jaringan distribusi yang terbagi menjadi beberapa gardu induk, yang selanjutnya didistribusikan melalui penyulang-penyulang yang ada pada gardu induk ke Jaringan Tegangan Menengah atau disebut saluran distribusi primer. Kemudian, pada distribusi primer, tenaga listrik disalurkan ke beban atau konsumen industri besar. Setelah melewati JTM, saluran listrik di turunkan kembali ke tegangan rendah 220/380 V atau yang bisaa disebut JTR untuk kebutuhan konsumen rumah tangga atau industri kecil rumahan. Saluran 220/380 V merupakan saluran distribusi sekunder [3]. 


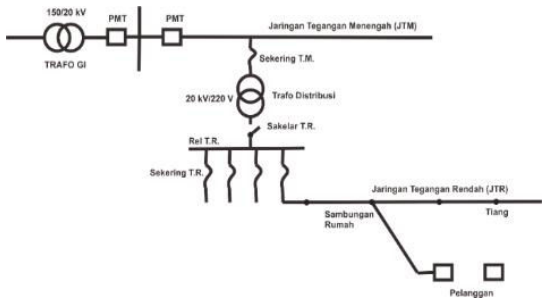

Gambar 1. Sistem distribusi tenaga listrik.

Sumber : Marsudi 2006, Operasi Sistem Tenaga Listrik

\section{B. Operasi Paralel Transformator}

Sistem tenaga listrik menggunakan trafo yang terhubung paralel dengan tujuan keandalan dan kualitas daya yang lebih baik serta menjaga kontinyuitas penyaluran konsumen. Untuk operasi paralel trafo harus memiliki polaritas, rasio dan sudut fasa yang sama atau kompatibel. Misalnya, transformator dari tegangan yang identik terhubung Yd1 dan Dy1 kompatibel untuk operasi paralel, tetapi pada trafo terhubung Yd1 dan Yd11 tidak bisa beroperasi paralel karena terjadi perbedaan sudut fasa $60^{\circ}$, Jika semua kondisi di atas sama, operasi paralel trafo mungkin masih bisa gagal untuk pembagian beban yang tidak sama [4]. Pembagian beban tergantung pada:
i. Impedansi Trafo
ii. Perbedaan kecil dalam rasio

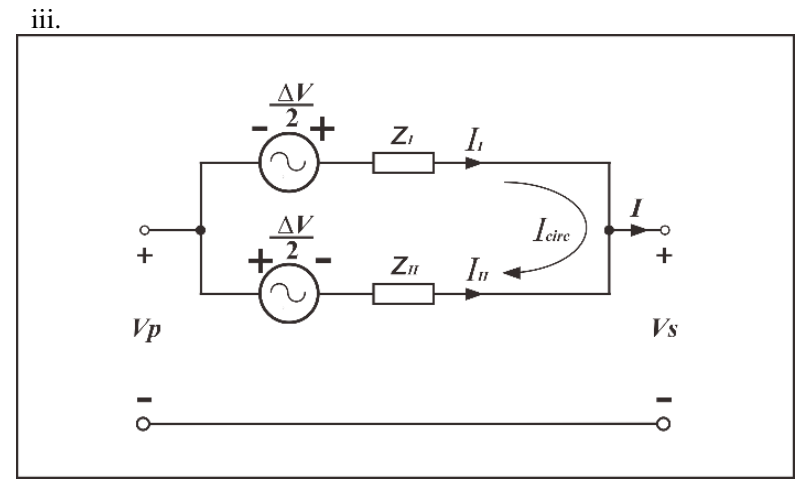

Gambar 2. Operasi Paralel Trafo [4].

Pada kondisi tidak berbeban $(I=0)$ terdapat additional circulating currents antar trafo (dalam nilai pu).

$$
I_{\text {circ }}=\frac{\Delta V}{Z_{I}+Z_{I I}} \approx \frac{\Delta a}{a_{n}} \frac{V_{p}}{Z_{I}+Z_{I I}} \approx \frac{\Delta a}{a_{n}} \frac{V_{s}}{Z_{I}+Z_{I I}}
$$

Oleh karena itu kita dapat menghitung arus cabang dengan mengasumsikan $\Delta V=0$, dan kemudian menambahkan circulating currents untuk mendapatkan arus total pada setiap trafo:

$$
\begin{aligned}
& I_{I}=I \frac{Z_{I I}}{Z_{I}+Z_{I I}}+I_{\text {circ }} \\
& I_{I I}=I \frac{Z_{I}}{Z_{I}+Z_{I I}}-I_{\text {circ }}
\end{aligned}
$$

Dimana:

$$
\begin{array}{ll}
I_{I} & : \text { arus beban trafo } 1 \\
I_{I I} & : \text { arus beban trafo } 2 \\
I & : \text { arus total beban trafo } 1 \text { dan trafo } 2 \\
Z_{I} & : \text { impedansi trafo } 1 \\
Z_{I} & : \text { impedansi trafo } 2
\end{array}
$$

\section{Operasi Paralel Penyulang}

Ketika penyulang dihubungkan secara paralel, hal yang harus diperhatikan adalah pembebanan penyulang yang saling berhubungan, dimana akan terjadi peningkatan arus setelah paralelisasi. Besar arus yang dihasilkan pada segmen kritis tergantung pada impedansi, beban saluran dan faktor daya, serta besar tegangan sumber dan sudut kedua penyulang. Untuk membuat keputusan operasional pada paralelisasi penyulang, juga harus diperhatikan cara yang tepat untuk memaksimalkan dan perbedaan perkiraan beban dalam ketepatan perkiraan sudut yang diharapkan. Dengan cara mengatur tegangan sumber dan mengatur LTCS trafo gardu induk [5].

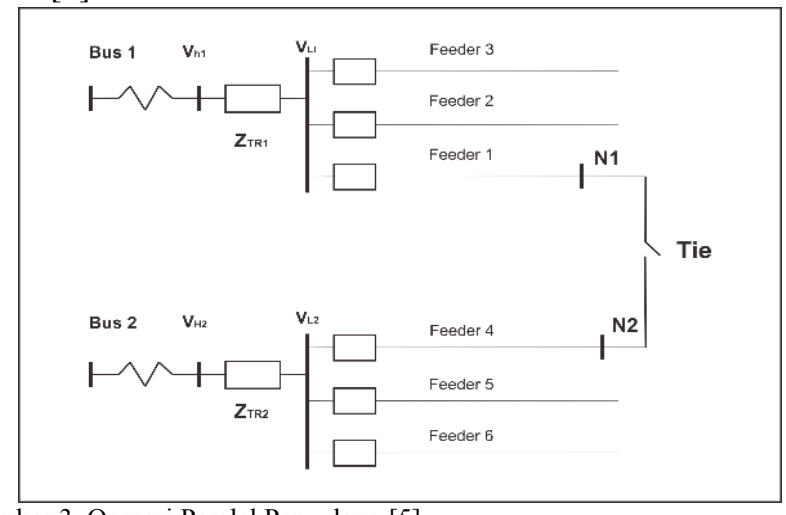

Gambar 3. Operasi Paralel Penyulang [5].

\section{Sistem Proteksi Gardu Induk}

Pada saat operasi paralel sistem proteksi yang bekerja adalah rele over current atau arus lebih. Rele arus lebih merupakan suatu jenis rele yang bekerja berdasarkan besarnya arus masukan dan bekerja bila besar arus masukan melebihi suatu harga tertentu yang telah diatur (Ip). Dimana Ip merupakan arus kerja yang dinyatakan menurut belitan sekunder dari trafo arus (CT). bila suatu gangguan terjadi di dalam daerah perlindungan rele, besarnya arus Ir juga dinyatakan terhadap belitan sekunder CT. Rele akan bekerja apabila memenuhi keadaan sebagai berikut:

$$
\begin{aligned}
& \text { Ir }>\text { Ip rele akan bekerja (trip) } \\
& \text { Ir }<\text { Ip rele tidak bekerja (blok) }
\end{aligned}
$$

Pada GI Srondol jenis rele arus lebih yang digunakan adalah kurva waktu terbalik normal (standard inverse) yang mana waktu kerjanya tergantung pada level besarnya arus hubung singkat, semakin besar maka semakin cepat kerjanya. Pada koordinasi rele invers berlaku untuk koordinasi arus dan waktu sekaligus.

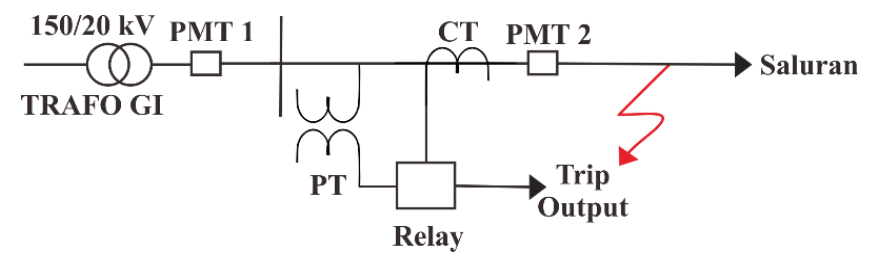

Gambar 4. Hubungan relay dalam sistem distribusi.

\section{PEMODELAN SISTEM}

Pemodelan sistem kelistrikan pada gardu induk Srondol Area Semarang Selatan ini tergabung dalam sistem yang 
besar, yang terdiri dari Grid Transmisi Jawa Bagian Tengah (TJBT), Transformator Daya, peralatan Proteksi seperti Circuit Breaker dan Recloser beserta rele dan alat sensing Current Transformer (CT), peralatan Switching seperti Load Break Switch (LBS) dan Kontaktor, saluran konduktor dan beban listrik yang di asumsikan sebagai Lump Load (terdiri dari beban motor dan beban statis). Pemodelan sistem gardu induk tersebur didasarkan pada data-data riil yang ada pada lapangan yang didapatkan dari PLN Area Pengatur Distribusi Jawa Tengah \& D.I. Yogyakarta, serta berdasarkan historis kasus gangguan padam trafo 2 di GI Srondol pada tanggal 25 September 2017.

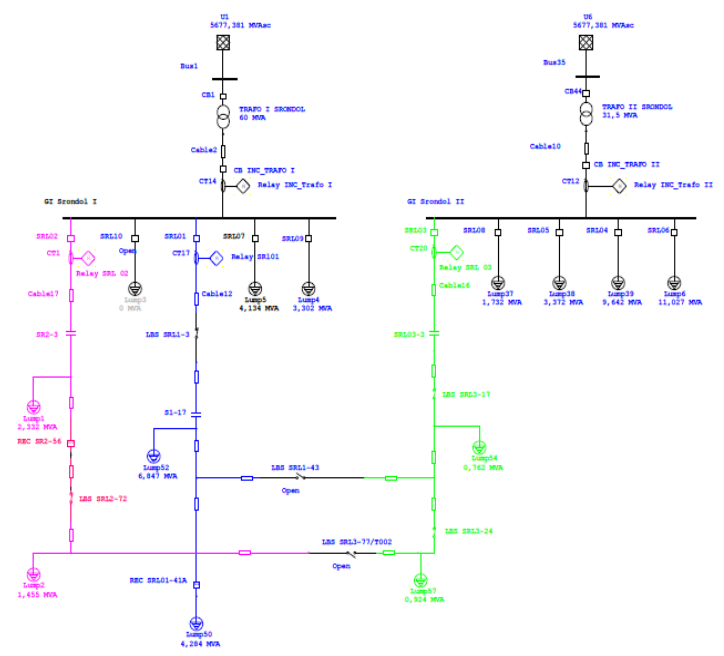

Gambar 5. Pemodelan Sistem Kelistrikan GI Srondol.

Peramodelan sistem ini menjelaskan sistem secara keseluruhan yang di simulasikan melalui software Electrical Transient Analysis Program (ETAP) 12.6.0. mulai skema aliran daya sebelum dan sesudah pengoperasian paralel, respon dari sistem koordinasi proteksi pada sisi penyulang dan incoming trafo, serta beberapa parameter-parameter seperti daya, arus listik dan tegangan yang terukur pada sistem sebagai acuan kondisi kestabilan sistem gardu induk tersebut.

\section{HASIL PERHITUNGAN DAN ANALISIS}

\section{A. Karakteristik Arus Saat Operasi Paralel}

Ketika pengoperasian paralel antara dua buah penyulang jaringan distribusi. Dimana kedua trafo tersebut memiliki nilai kapasitas dan impedansi yang berbeda maka akan terjadi pembagian arus yang melalui dua penyulang tersebut dan tentunya penambahan arus sirkulasi pada loop sekundernya.

Oleh karena itu untuk menganalisis besarnya nilai arus saat melakukan operasi paralel sangat dibutuhkan, untuk memastikan bahwa sistem dalam kondisi aman dan operasi paralel bisa bekerja dengan baik tanpa mengalami kegagalan.

1) Operasi Paralel Penyulang SRL 1 dan SRL 3

Ketika penyulang dihubungkan secara paralel, hal yang perlu diperhatikan adalah pembebanan trafo yang saling berhubungan, tegangan pada titik percabangan dan impedansi jaringan yang dihitung mulai dari belitan trafo hingga ke jaringan titik join keduanya berada.
Untuk menghitung besarnya peningkatan arus data-data yang diperlukan adalah beban tiap trafo dan impedansi total jaringan. Dan dengan menggunakan simulasi ETAP 12.6.0 dari analisis Load Flow bisa dilihat perbandingan nilai arus sebelum dan saat operasi paralel terjadi pada Tabel 1.

Tabel 1.

Hasil Arus Saat Operasi Paralel SRL 1 dan SRL 3

\begin{tabular}{ccccc}
\hline \hline \multirow{2}{*}{ Keypoint } & \multicolumn{2}{c}{ Sebelum Paralel } & \multicolumn{2}{c}{ Setelah Paralel } \\
\cline { 2 - 5 } & ETAP & Pengukuran & ETAP & Pengukuran \\
\hline Trafo I & $651 \mathrm{~A}$ & $650 \mathrm{~A}$ & $906 \mathrm{~A}$ & $897 \mathrm{~A}$ \\
Trafo II & $799 \mathrm{~A}$ & $800 \mathrm{~A}$ & $591 \mathrm{~A}$ & $572 \mathrm{~A}$ \\
SRL 1 & $324 \mathrm{~A}$ & $324 \mathrm{~A}$ & $588 \mathrm{~A}$ & $570 \mathrm{~A}$ \\
SRL 3 & $51 \mathrm{~A}$ & $51 \mathrm{~A}$ & $260 \mathrm{~A}$ & $278 \mathrm{~A}$ \\
SRL1-43 & - & - & $297 \mathrm{~A}$ & $292 \mathrm{~A}$ \\
\hline \hline
\end{tabular}

Dengan menggunakan simulasi Transent Stability Analysis pada ETAP 12.6.0, dapat dilihat respon arus pada setiap kondisi ketika operasi paralel berlangsung yang mengalir melewati incoming trafo I, incoming trafo II, penyulang SRL 1 dan penyulang SRL 3.

Dalam pengoperasian penyulang SRL 1 dan SRL 3 ini terjadi 3 kondisi pada sistem. Yaitu, Kondisi pertama (1) adalah karakteristik arus saat sistem belum terjadi paralelisasi antara kedua penyulang, kondisi kedua (2) adalah karakteristik arus tepat saat operasi paralel kedua penyulang berlangsung (ketika LBS SRL1-43 switch join), dan kondisi ketiga (3) adalah karakteristik arus setelah operasi paralel berlangsung dalam hal ini respon yang terjadi adalah tripnya CB penyulang SRL 1 karena arus ketika operasi paralelnya melebihi nilai setting proteksi yang telah ditentukan.

Sehingga perubahan dan karakteristik nilai arus pada masing-masing keypoint bisa dilihat pada gambar-gambar berikut,

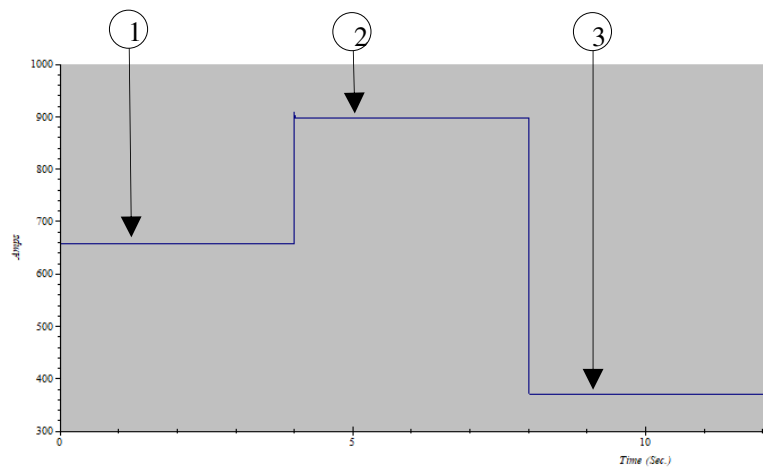

Gambar 6. Karakteristik Arus Pada Incoming Trafo I.

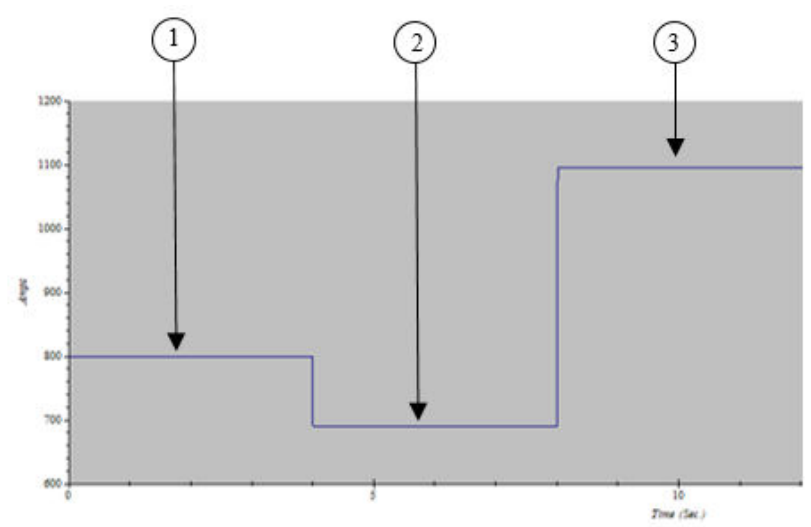

Gambar 7. Karakteristik Arus Pada Incoming Trafo II. 


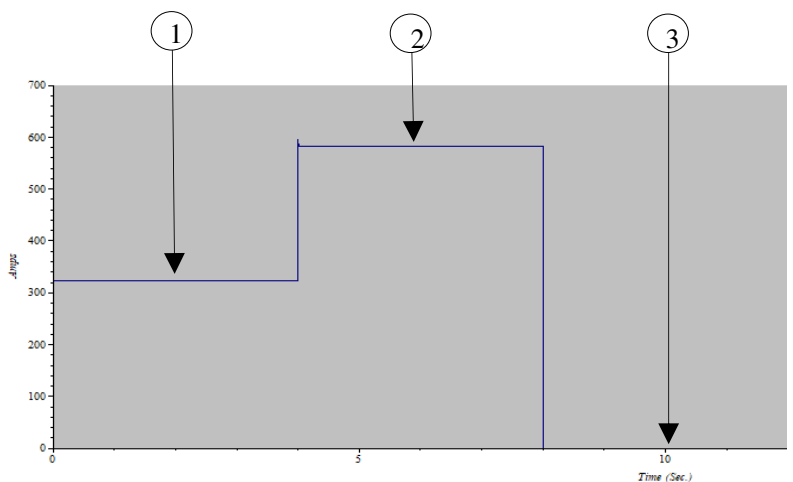

Gambar 8. Karakteristik Arus Pada Penyulang SRL 1.

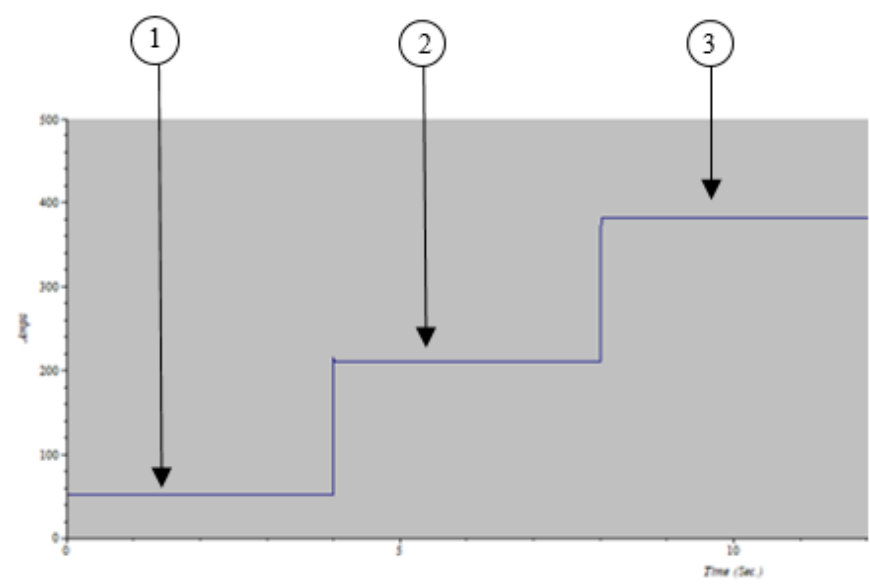

Gambar 9. Karakteristik Arus Pada Penyulang SRL 3.

\section{2) Operasi Paralel Penyulang SRL 2 dan SRL 3}

Seperti pada perhitungan operasi paralel antara penyulang SRL 1 dan SRL 3. Untuk membandingkan hasil pengoperasian paralel yang disuplai dari penyulang lain, juga perlu dilakukan perhitungan untuk mengetahui nilai peningkatan arus yang terjadi ketika penyulang SRL 2 dan SRL 3 saat paralelisasi.

Sama dengan operasi paralel sebelumnya untuk menghitung besarnya peningkatan arus data-data yang diperlukan adalah beban tiap trafo dan impedansi total jaringan sebelum diparalel. Dan dengan menggunakan simulasi ETAP 12.6.0 dari analisis Load Flow bisa dilihat perbandingan nilai arus sebelum dan saat operasi paralel terjadi pada Tabel 2.

Tabel 2.

Hasil Arus Saat Operasi Paralel SRL 2 dan SRL 3

\begin{tabular}{ccccc}
\hline \hline \multirow{2}{*}{ Keypoint } & \multicolumn{2}{c}{ Sebelum Paralel } & \multicolumn{2}{c}{ Setelah Paralel } \\
\cline { 2 - 5 } & ETAP & Pengukuran & ETAP & Pengukuran \\
\hline Trafo I & $651 \mathrm{~A}$ & $650 \mathrm{~A}$ & $802 \mathrm{~A}$ & $798 \mathrm{~A}$ \\
Trafo II & $799 \mathrm{~A}$ & $800 \mathrm{~A}$ & $670 \mathrm{~A}$ & $671 \mathrm{~A}$ \\
SRL 2 & $111 \mathrm{~A}$ & $111 \mathrm{~A}$ & $277 \mathrm{~A}$ & $258 \mathrm{~A}$ \\
SRL 3 & $51 \mathrm{~A}$ & $51 \mathrm{~A}$ & $149 \mathrm{~A}$ & $141 \mathrm{~A}$ \\
SRL3-77 & - & - & $182 \mathrm{~A}$ & $179 \mathrm{~A}$ \\
\hline \hline
\end{tabular}

Dengan menggunakan simulasi Transent Stability Analysis pada ETAP 12.6.0, dapat dilihat respon arus pada setiap kondisi ketika operasi paralel berlangsung yang mengalir melewati incoming trafo I, incoming trafo II, penyulang SRL 2 dan penyulang SRL 3.
Dalam pengoperasian penyulang SRL 2 dan SRL 3 ini juga terjadi 3 kondisi pada sistem. Yaitu, Kondisi pertama (1) adalah karakteristik arus saat sistem belum terjadi paralelisasi antara kedua penyulang, kondisi kedua (2) adalah karakteristik arus tepat saat operasi paralel kedua penyulang berlangsung (ketika LBS SRL3-77 switch join), dan kondisi ketiga (3) adalah karakteristik arus setelah operasi paralel berlangsung dalam hal ini respon yang terjadi adalah tripnya CB penyulang SRL 3 sebagai proses pelimpahan beban dari trafo 2 ke trafo 1 GI Srondol.

Sehingga perubahan dan karakteristik nilai arus pada masing-masing keypoint bisa dilihat pada gambar-gambar berikut,

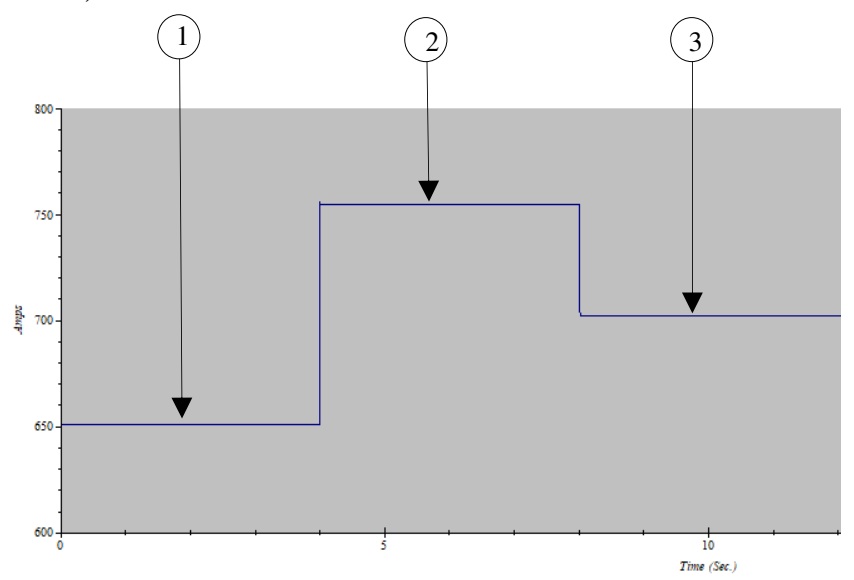

Gambar 10. Karakteristik Arus Pada Incoming Trafo I.

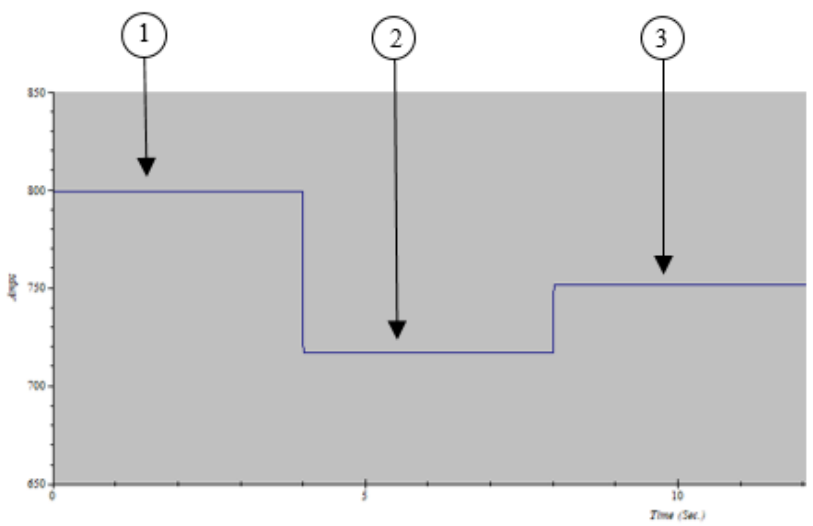

Gambar 11. Karakteristik Arus Pada Incoming Trafo II.

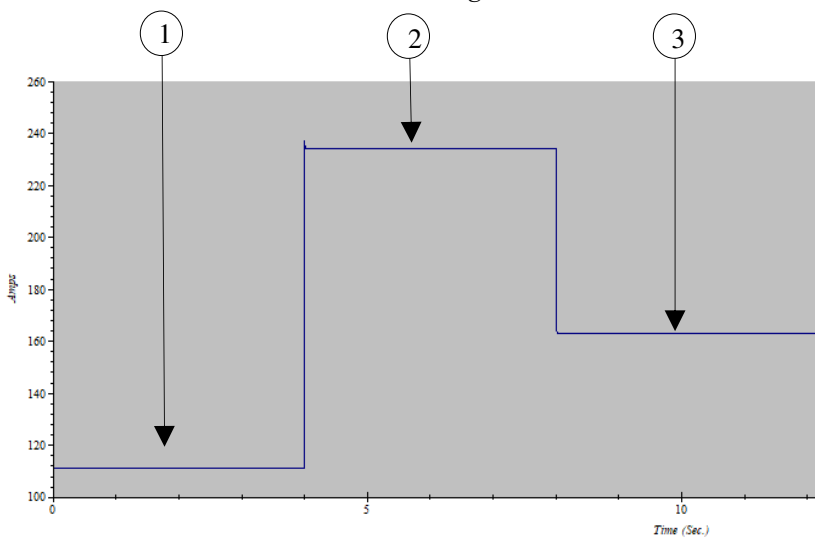

Gambar 12. Karakteristik Arus Pada Penyulang SRL 2. 


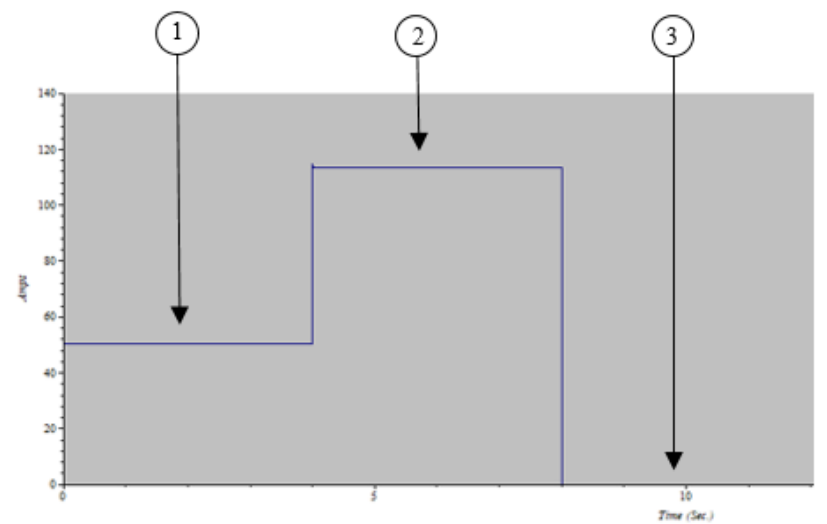

Gambar 13. Karakteristik Arus Pada Penyulang SRL 3.

\section{B. Setting Proteksi saat Operasi Paralel}

Untuk mengetahui keberhasilan atau kegagalan sistem saat operasi paralel jaringan distribusi berlangsung, maka perlu memperhatikan kondisi existing setting koordinasi proteksi yang ada dengan penambahan arus ketika proses paralelisasi. Pada tugas akhir ini setting proteksi yang diperhatikan hanya pada bagian circuit breaker yang berada di incoming trafo dan penyulang GI Srondol yang mengalami pengoperasian paralel jaringan distribusi.

Berikut adalah data peralatan proteksi dan seting proteksi pada gardu induk Srondol Area Semarang:

Tabel 3.

Setting Relay OCR GI Srondol

\begin{tabular}{llllll}
\hline \hline \multicolumn{1}{c}{ Relay } & \multicolumn{1}{c}{ Merk } & \multicolumn{1}{c}{$\mathrm{I}>$} & \multicolumn{1}{c}{$\mathrm{I}>>$} & \multicolumn{1}{c}{ TMS } & $\mathrm{t}>>$ \\
\hline Inc. Trafo I & AREVA P122 & 2080A & $6940 \mathrm{~A}$ & 0,25 & $0,7 \mathrm{~s}$ \\
Inc. Trafo II & AREVA P122 & 990A & $3300 \mathrm{~A}$ & 0,2 & $0,7 \mathrm{~s}$ \\
SRL 1 & AREVA P123 & 480A & $3480 \mathrm{~A}$ & 0,25 & $0,3 \mathrm{~s}$ \\
SRL 2 & AREVA P123 & 480A & 3480A & 0,25 & $0,3 \mathrm{~s}$ \\
SRL 3 & GE SR 350 & 480A & 1920A & 0,15 & $0,3 \mathrm{~s}$ \\
\hline \hline
\end{tabular}

\section{1) Proteksi saat Operasi Paralel SRL 1 dan SRL 3}

Pada kondisi sebelum paralel terlihat beban pada trafo 2 hampir overload dengan arus sebesar 799 A. Sedangkan pada trafo 1 arus sebesar $651 \mathrm{~A}$, maka untuk mengurangi beban pada trafo 2 perlu dilakukan pelimpahan beban ke trafo 1 melalui penyulang SRL 3 yang disuplai oleh trafo 2 dengan arus beban 51 A ke SRL 1 yang disuplai oleh trafo 1 dengan arus beban $324 \mathrm{~A}$.

Untuk melakukan proses pelimpahan beban maka jaringan harus diparalel terlebih dahulu dengan menutup LBS SRL1-43 menjadi keadaan normally close. Pada kondisi paralel jaringan ini terjadi peningkatan arus yang tinggi pada trafo 1 dan mengalir melalui penyulang SRL 1 sebesar 588 A. Dengan melihat setting proteksi pada penyulang SRL 1, maka rele pada penyulang SRL 1 bekerja karena dianggap sebagai arus gangguan sehingga circuit breaker terbuka (trip). Kerja rele penyulang SRL 1 ditunjukkan pada Gambar 14.

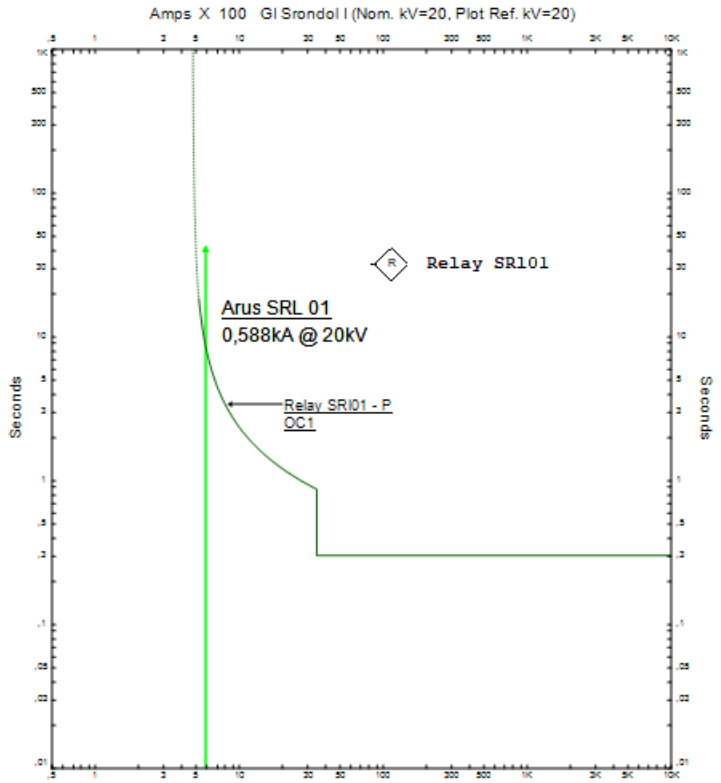

Gambar 14. Kurva Rele SRL 1 saat operasi paralel.

Akibat dari lepasnya penyulang SRL 1, maka terjadi pelimpahan beban ke penyulang SRL 3. Dari hasil simulasi terlihat dimana arus beban pada penyulang SRL 3 menjadi sebesar 362 A, tetapi pada sisi incoming trafo 2 nya menjadi sebesar 1094 A. Dengan melihat setting proteksi pada penyulang SRL 3 dan incoming trafo 2, maka rele pada incoming trafo 2 yang bekerja karena dianggap sebagai arus gangguan sehingga circuit breaker terbuka (trip) yang mana mengakibatkan pemadaman total pada GI Srondol II. Kerja rele incoming trafo II ditunjukkan pada Gambar 15.

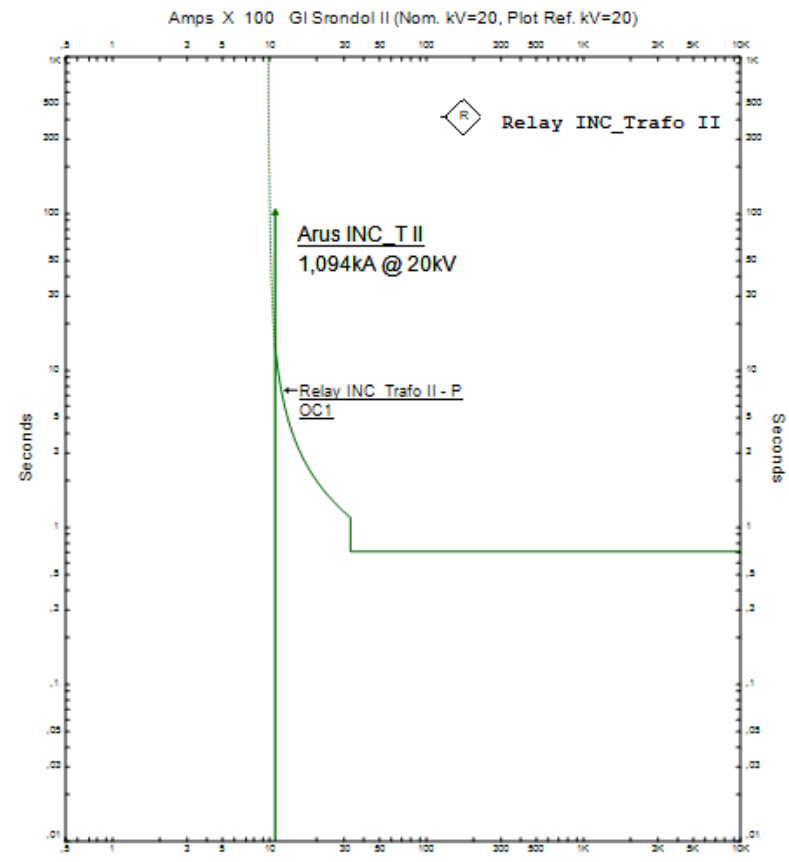

Gambar 15. Kurva Rele Incoming Trafo II saat SRL 1 Trip

penyulang dihubungkan secara paralel, hal yang perlu diperhatikan adalah pembebanan trafo yang saling berhubungan, tegangan pada titik percabangan dan impedansi jaringan yang dihitung mulai dari belitan trafo hingga ke 
jaringan titik join keduanya berada. Dimana akan terjadi peningkatan arus setelah paralelisasi terjadi.

2.) Proteksi saat Operasi Paralel SRL 2 dan SRL 3

Untuk Operasi paralel antara penyulang SRL 2 dan SRL 3, Dari hasil simulasi ETAP 12.6.0 pada kondisi paralel jaringan ini peningkatan arus yang terjadi cukup stabil dan relatif kecil. Pada incoming trafo 1 arus yang mengalir sebesar 802 A dan pada penyulang SRL 2 sebesar 277 A. Dengan melihat setting koordinasi proteksi pada GI Srondol 1, maka tidak ada rele yang bekerja karena masih dibawah arus settingnya. Sedangkan di GI Srondol 2, pada incoming trafo 2 arus yang mengalir sebesar 670 A dan pada penyulang SRL 3 sebesar 149 A. Dengan melihat setting koordinasi proteksi pada GI Srondol 2, maka tidak ada rele yang bekerja karena masih dibawah arus settingnya.

Oleh karena tidak ada rele prtoeksi yang bekerja baik pada GI Srondol 1 maupun GI Srondol 2. Maka operasi paralel dikatakan berhasil dan proses pelimpahan beban untuk mengurangi beban overload pada trafo 2 melalui penyulang SRL 3 ke penyulang SRL 2 dapat dilakukan dengan membuka CB pada SRL 3.

\section{KESIMPULAN}

Berdasarkan hasil yang didapatkan dari perhitungan dan analisis pada tugas akhir ini, didapatkan kesimpulan sebagai berikut:

1. Pada kondisi normal dari hasil simulasi Load Flow ETAP diperoleh trafo 2 GI Srondol mengalami overload sebesar 799 A, sehingga diperlukan pelimpahan beban dengan cara mengoperasikan paralel jaringan terlebih dahulu.
2. Pada saat operasi paralel penyulang SRL 1 dan SRL 3 terjadi peningkatan arus yang signifikan pada penyulang SRL 1 sebesar 588 A yang mengakibatkan PMTnya menjadi trip, sehingga terjadi pelimpahan beban ke trafo 2 menjadi sebesar 1094 A dan mengakibatkan pemadaman total pada trafo 2 .

3. Pada saat operasi paralel penyulang SRL 2 dan SRL 3 peningkatan arus yang terjadi lebih kecil, sehingga sistem masih dalam kondisi aman dan proses pelimpahan beban berhasil dilakukan.

4. Hal - hal yang perlu diperhatikan dalam pengoperasian paralel jaringan distribusi diantaranya, beban masingmasing trafo, deviasi tegangan antara ujung penyulang, panjang saluran titik join kedua penyulang serta kecepatan peralatan switching dan waktu koordinasi protkesinya.

\section{DAFTAR PUSTAKA}

[1] A. J. Firdaus, "Analisa Beban Section untuk Menentukan Alternatif Manuver Jaringan Distribusi $20 \mathrm{kV}$ Penyulang BRG-3 PT PLN (Persero) Unit Layanan Salatiga," JTET J. Tek. Elektro Ter., vol. 2, no. 3, 2013.

[2] P. Bernardon, L. Comassetto, F. D. Veiga, and L. N. Canha, "Studies of paralelism in distribution networks served by differentsource substations," Electr. Power Syst. Res, vol. 78, no. 3, pp. 450457, 2007.

[3] A. Kadir, Distribusi Tenaga Listrik. Jakarta: Universitas Indonesia, 2000.

[4] P. McLean, "Power Circuit Theory," Sydney, 2017.

[5] A. Berman and N. Markushevich, "Analysis of three-phase paralel distribution feeders fed from different substations," in Transmission and Distribution Conference and Exposition, 2010 IEEE PES, 2010, pp. $1-8$. 